\title{
Determination of Thallium(I) by Hybrid Mesoporous Silica (SBA-15) Modified Electrode
}

\author{
Geeta Rani and Sanjay Singh \\ Department of Chemistry, M.M.H. College, Ghaziabad 201001, India \\ Correspondence should be addressed to Sanjay Singh; drsanjay.s77@gmail.com \\ Received 6 October 2015; Revised 1 March 2016; Accepted 7 March 2016 \\ Academic Editor: Grzegorz Milczarek
}

Copyright (C) 2016 G. Rani and S. Singh. This is an open access article distributed under the Creative Commons Attribution License, which permits unrestricted use, distribution, and reproduction in any medium, provided the original work is properly cited.

\begin{abstract}
Chemically modified mesoporous silica material (SBA-15) was used for the construction of $\mathrm{Tl}(\mathrm{I})$ selective carbon paste electrode. The best response was found with the electrode containing $10 \%$ modifier as electrode material. The electrode has a lower detection limit of $6.0 \times 10^{-9} \mathrm{M}$ in a working concentration range of $1.0 \times 10^{-8}-1.0 \times 10^{-1} \mathrm{M}$. The selectivity coefficient calculated by match potential method (MPM) shows the high selectivity of electrode towards Tl(I) over other tested ions. The electrode was successfully applied as an indicator electrode for the titration of $0.01 \mathrm{M} \mathrm{TINO}_{3}$ solution with standards EDTA solution and for sequential titration of mixture of different anions.
\end{abstract}

\section{Introduction}

Thallium is a soft and pliable metal. The metal is obtained as a byproduct of refining zinc or lead. The $\mathrm{Tl}(\mathrm{I})$ salts are soluble in water and easily absorbed in human body. Thallium compounds are quite toxic and some have been used as rat poisons $[1,2]$. Thus the determination of thallium metal content in solution is a subject of importance particularly in pharmaceutical, medicinal, and environmental point of view. The ion selective electrodes are good candidature of the traces determination of metal ions because they calculated the activity of ion instead of concentration. Several potentiometric PVC based electrodes have been used for the selective determination of $\mathrm{Tl}(\mathrm{I})$ during the last several years. But most of them have low concentration range, high detection limit, slow response mechanism, and small life time [3-5].

Silica is widely used for the synthesis of various mesoporous materials because it is chemically inert, inexpensive, and easily available and has high thermal stability. The order mesoporous silica was first reported in 1992; since then various mesoporous silica materials have been synthesized. The SBA (Santa Barbara Amorphous) type silica is a high order material possessing a regular two-dimensional hexagonal arrangement of pores. The SBA-15 exhibits large surface area, large pore size of the same dimensions, and thick framework walls, which helps to capture the target species
[6-9]. The presence of active hydrophilic hydroxyl groups at the surface provides the suitable environment for chemical modification of the material. The covalent interaction between mesoporous silica and organic binder provides the extra stability to the material which enhances the life time, selectivity, sensitivity, and potential response of the material. The rapid complexation kinetics at electrode solution eliminates the ohmic resistance which improves the selectivity, sensitivity, and potential response of the electrode. Thus a chemically modified electrode based on mesoporous SBA-15 was constructed for the selective determination of $\mathrm{Tl}(\mathrm{I})$ in various samples.

\section{Experimental Section}

2.1. Reagents and Instruments. The analytical grade reagents, 2-[5-(chloromethyl)-1,2,4-oxadiazol-3-yl]-3-methylpyridine (COMP), 3-(triethoxysilyl)propyl amine (TESPA), and SBA15, were purchased from Sigma-Aldrich (India). The graphite powder with $1-2 \mu \mathrm{m}$ particle size, paraffin oil, and metal salts were purchased from Merck (India). Acetone, $\mathrm{NaOH}$, ethanol, toluene, and other chemicals were purchased from local pharmaceutical companies. All the reagents were used without further purification. The test solutions of various metal cations were prepared from the corresponding analytical grade metal salts and were diluted to the desired 


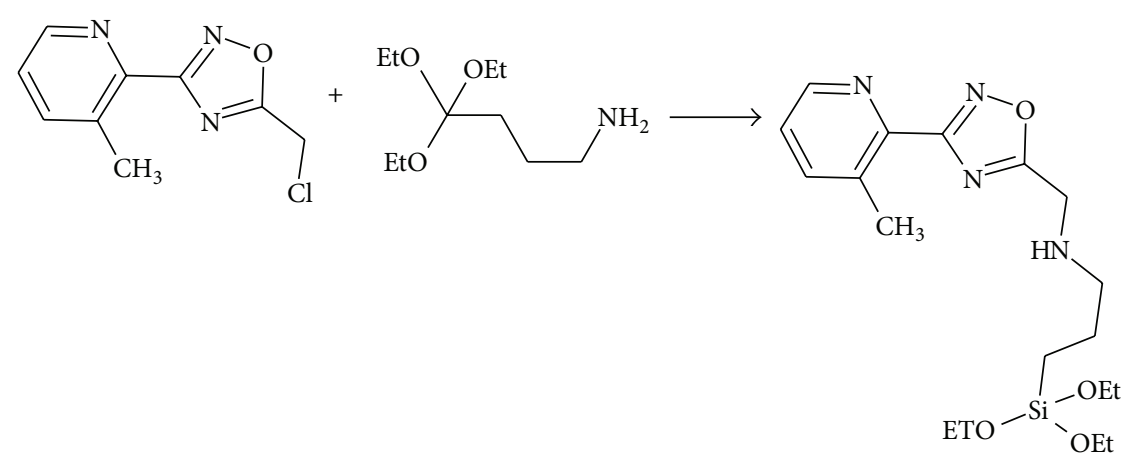

SCHEME 1
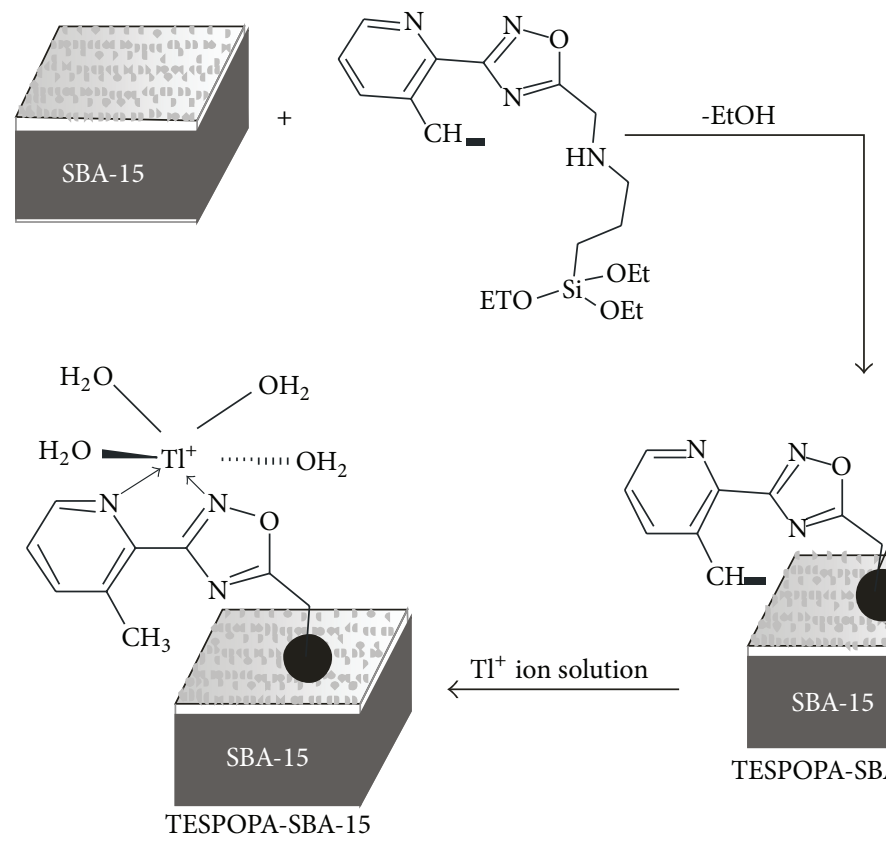

$\longleftarrow \mathrm{Tl}^{+}$ion solution

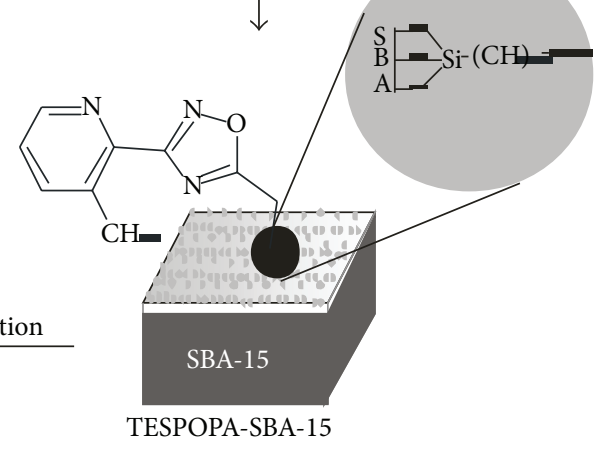

SCHEME 2

concentration. Double distilled water was used through the process.

All the potential was measured with the help of digital potentiometer (Equiptronics EQ-602, Mumbai, India) using modified carbon paste electrode in conjunction with an ECIL, India double junction $\mathrm{Ag} / \mathrm{AgCl}$ reference electrode containing $10 \%(\mathrm{w} / \mathrm{w})$ potassium nitrate solution in the outer compartment. The $\mathrm{pH}$ of test solutions was measured with a conventional glass $\mathrm{pH}$ electrode.

2.2. 3-(Triethoxysilyl)-N-\{[3-(3-methylpyridin-2-yl)-1,2,4-oxadiazol-5-yl]methyl propan-1-amine (TMPA). A solution of 2-[5-(chloromethyl)-1,2,4-oxadiazol-3-yl]-3-methylpyridine (COMP) (0.001 mole) in $50 \mathrm{~mL}$ THF was added to a solution of 0.01 mole of 3-(triethoxysilyl)propyl amine (TESPA) in $10 \mathrm{~mL} \mathrm{THF}$ at $0^{\circ} \mathrm{C}$. The solution was refluxed for $1 \mathrm{~h}$ at room temperature producing an oily product. The excess of solvent and unused reactants were removed at reduced pressure. The residue was washed with ethanol producing a white solid
(Scheme 1). The structure of solid was analyzed by ${ }^{1} \mathrm{H}-\mathrm{NMR}$ and ${ }^{13} \mathrm{C}-\mathrm{NMR}$ spectra.

${ }^{1} \mathrm{H} \mathrm{NMR}\left(\mathrm{CDCl}_{3}\right): \delta(\mathrm{ppm})=8.23(\mathrm{t}, 1 \mathrm{H}, \mathrm{NH}), 7.86(\mathrm{~s}, 1 \mathrm{H}$, Ar), 7.83 (t, 1H, Ar), $7.82(\mathrm{~s}, 1 \mathrm{H}, \mathrm{Ar}), 3.71\left(\mathrm{q}, 2 \mathrm{H}, \mathrm{CH}_{2}\right), 3.53(\mathrm{~d}$, $\left.2 \mathrm{H}, \mathrm{CH}_{2}\right), 1.70\left(\mathrm{~m}, 2 \mathrm{H}, \mathrm{CH}_{2}\right), 1.68\left(\mathrm{~s}, 2 \mathrm{H}, \mathrm{CH}_{2}\right), 1.28(\mathrm{~s}, 3 \mathrm{H}$, $\left.\mathrm{CH}_{3}\right), 1.22\left(\mathrm{t}, 9 \mathrm{H}, \mathrm{CH}_{3}\right), 0.71\left(\mathrm{t}, 6 \mathrm{H}, \mathrm{CH}_{2}\right)$.

${ }^{13} \mathrm{C} \mathrm{NMR}\left(\mathrm{CDCl}_{3}\right): \delta(\mathrm{ppm})=(7 \mathrm{C}$, aromatic $) ; 167.2,166.7$, 166.4, 166.2, 165.6, 164.3, 164.2 (11C, aliphatic); 80.6, 40.5, 40.2, $40.1,39.2,38.6,38.5,38.4,35.8,35.3,35.1$.

2.3. Synthesis of TMPA-SBA-15. The organofunctionalized TMPA-SBA-15 hybrid was obtained by copolymerization of TMPA and SBA- 15 under controlled conditions at $30^{\circ} \mathrm{C}$. A mixture of SBA-15 (3 g in $100 \mathrm{~mL}$ of dry toluene) and TMPA $(0.001 \mathrm{~mol})$ was refluxed for $10 \mathrm{~h}$. The resultant precipitate was air dried. The final product was then washed with ethanol and acetone for $20 \mathrm{~h}$ and then dried for $24 \mathrm{~h}$ at room temperature and for $1 \mathrm{~h}$ at $100^{\circ} \mathrm{C}$ (Scheme 2). The elemental analysis (weight percentage of $\mathrm{N}$ ) indicates that $0.912 \mathrm{mmol} / \mathrm{g}$ of the 
TABLE 1: Effect of electrode components on response characters of modified carbon paste electrode.

\begin{tabular}{|c|c|c|c|c|c|c|c|}
\hline & \multicolumn{3}{|c|}{ Composition, \% (w/w) } & \multirow{2}{*}{ Slope (mV/decay) } & \multirow{2}{*}{ Linear range $(\mathrm{M})^{\mathrm{a}}$} & \multirow{2}{*}{ LOD (M) } & \multirow{2}{*}{ Response time (s) } \\
\hline & TMPA-SBA-15 & Graphite powder & Paraffin oil & & & & \\
\hline CPE1 & 0 & 75 & 25 & $10.6 \pm 2.5$ & - & - & - \\
\hline CPE2 & 2 & 75 & 23 & $21.6 \pm 1.4$ & $6.0 \times 10^{-7}-1.0 \times 10^{-1}$ & $8.0 \times 10^{-6}$ & 25 \\
\hline CPE3 & 3 & 75 & 22 & $24.4 \pm 1.2$ & $1.2 \times 10^{-7}-1.0 \times 10^{-1}$ & $5.8 \times 10^{-7}$ & 22 \\
\hline CPE4 & 5 & 75 & 20 & $26.3 \pm 1.2$ & $1.2 \times 10^{-7}-1.0 \times 10^{-1}$ & $4.3 \times 10^{-7}$ & 18 \\
\hline CPE5 & 7 & 75 & 18 & $28.4 \pm 1.1$ & $1.4 \times 10^{-7}-1.0 \times 10^{-1}$ & $2.5 \times 10^{-7}$ & 15 \\
\hline CPE6 & 8 & 75 & 17 & $31.4 \pm 1.1$ & $5.0 \times 10^{-7}-1.0 \times 10^{-1}$ & $1.8 \times 10^{-7}$ & 12 \\
\hline CPE7 & 9 & 75 & 26 & $35.6 \pm 1.1$ & $2.0 \times 10^{-7}-1.0 \times 10^{-1}$ & $1.2 \times 10^{-7}$ & 10 \\
\hline CPE8 & 10 & 75 & 15 & $42.4 \pm 1.0$ & $1.0 \times 10^{-8}-1.0 \times 10^{-1}$ & $6.0 \times 10^{-9}$ & 8 \\
\hline CPE9 & 10 & 74 & 16 & $42.4 \pm 1.0$ & $1.1 \times 10^{-8}-1.0 \times 10^{-1}$ & $6.0 \times 10^{-9}$ & 8 \\
\hline CPE10 & 11 & 73 & 16 & $40.8 \pm 1.0$ & $5.1 \times 10^{-8}-1.0 \times 10^{-1}$ & $7.2 \times 10^{-9}$ & 8 \\
\hline CPE11 & 12 & 69 & 19 & $40.2 \pm 1.0$ & $5.3 \times 10^{-8}-1.0 \times 10^{-1}$ & $7.3 \times 10^{-9}$ & 8 \\
\hline CPE12 & 15 & 65 & 20 & $38.6 \pm 1.0$ & $5.6 \times 10^{-8}-1.0 \times 10^{-1}$ & $7.6 \times 10^{-9}$ & 8 \\
\hline
\end{tabular}

${ }^{\mathrm{a}}$ Mean value \pm standard deviation (three measurements).

hybrid was bonded on the surface of the SBA-15. The Xray diffraction pattern of TMPA-SBA-15 was found to be of typical hexagonal centered at $23 \pm 1$ and $28.4 \pm 1 \AA$, respectively. It was also observed that the structure SBA-15 remains almost the same after bonding with organic modifier.

2.4. Preparation of Carbon Paste Modified Electrode. The modified silica based carbon paste electrode was prepared by mixing fixed amount of graphite powder, paraffin oil, and TMPA-SBA-15. All the components were added in weight percentage. The components stir till the homogenous paste was obtained. The paste was than filled into a glass tube of $2 \mathrm{~mm}$ diameter. A copper wire was inserted from the opposite end to the glass tube for electrical contact. The electrode was removed from the tube and smoothed with the help of bond paper. For batter complexation kinetics at electrode surface a new electrode surface was generated by removing extra carbon paste and scratching the old electrode surface. The electrode surface was than conditioned by $0.001 \mathrm{M}$ solution of $\mathrm{TlCl}$ at $\mathrm{pH} 4.8$. The $\mathrm{pH}$ of solution was adjusted by phosphate buffer solution $[10,11]$.

The following cell assembly was used for potentiometric investigations:

$\mathrm{Ag}, \mathrm{AgCl}(\mathrm{s}) \mid 10 \%, \mathrm{KCl}(\mathrm{l}) \|$ test solution| modified carbon paste electrode.

2.5. Preparation of Sample Solution. The waste water samples were collected from the different local areas. Recovery experiments were conducted by spiking the water samples with appropriate amount of $\mathrm{Tl}_{2} \mathrm{SO}_{4}$. A test solution of hairs of cattle crazing around river was prepared as follows.

The hairs $(0.05 \mathrm{gm})$ were washed with THF, ethanol, and distilled water and burned in a muffle furnace at $460^{\circ} \mathrm{C}$. The residue was dissolved in concentrated nitric acid and evaporated till the solid residue was obtained. The obtained residue was than dissolved in water to get clear solution. The test solutions of sample were obtained by taking fixed volume of clear solution of the residue.

\section{Results and Discussions}

The functionalized mesoporous material is an effective material for the determination of metal ions from solution. The modifier loaded on the surface of the mesoporous silica (SBA15) material increases the conductivity of the material. The silica material provides the extra flexibility to the organic modifier to bind with different metal ions. The use of modified silica material could also avoid the background potential caused by direct use of polar binding material. The response mechanism of modified silica carbon paste electrode is based on the rapid complexation kinetics at electrode solution interface. The appropriate amount of electrode material can give the best possible response mechanism; therefore the electrodes of varying amount of TMPA-SBA-15, graphite powder, and paraffin oil were constructed and their response characters were recorded (Table 1).

The potential generated in absence of electroactive material due to some impurities is called background potential which may affect the potential response of the electroactive species. Thus the electrode without TMPA-SBA-15 (CPE1) was prepared and its potential response was recorded. The electrode CPE1 shows a nonlinear potentiometric response with the slope of $10.6 \pm 2.5$ (mV/decay of activity). To investigate the effect of electrode components on potential response the electrodes of different compositions were prepared. The data presented in Table 1 indicates that the increasing amount of hybrid TMPA-SBA-15 improves the slope of calibration curve; linear concentration range; and lower detection limit (LOD). The electrode with $2 \%(\mathrm{w} / \mathrm{w})$ TMPA-SBA-15 (CPE2) as electroactive material has a slope of $21.6 \pm 1.4(\mathrm{mV} /$ decay of activity) and LOD of $8.0 \times 10^{-6}$ in a liner concentration range of $6.0 \times 10^{-7}-1.0 \times 10^{-1} \mathrm{M}$. The electrode with $3-7 \%(\mathrm{w} / \mathrm{w})$ TMPA-SBA-15 as electroactive material hardly improves the response characters of the electrode. However $8-10 \%$ of the TMPA-SBA-15 has significant effect on working concentration range and LODs (CPE6, CPE7, CPE8, and CPE9). It was also observed that the electrode of the composition of $10 \%$ TMPA-SBA-15, 75\% graphite powder, and 15\% paraffin oil 


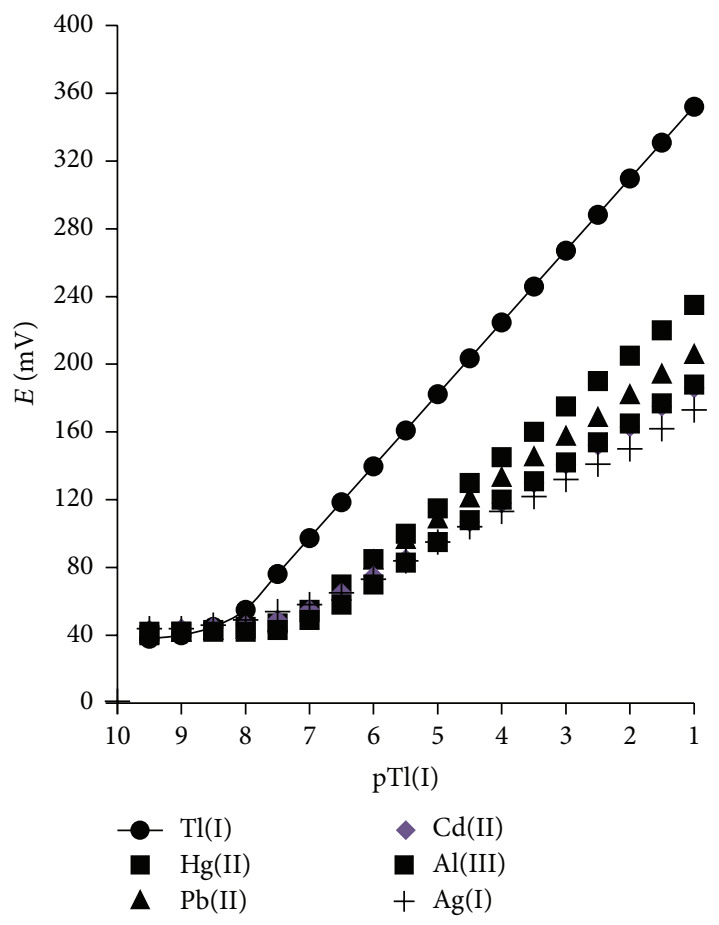

Figure 1: Potential response of CPE8 for different cations.

shows the best possible response in terms of slope, working concentration range, and LOD. The CPE8 has a slope of $42.4 \pm$ 1.0 (mV/decay of activity), LOD of $6.0 \times 10^{-9}$ in a liner concentration range of $1.0 \times 10^{-8}-1.0 \times 10^{-1} \mathrm{M}$ for $\mathrm{Tl}(\mathrm{I})$ ion. The potential response of CPE8 towards different cations for whole range of activity of cations is shown in Figure 1. After considering all the factors and response characters the CPE8 was selected as the most optimized electrode and used for further investigations.

3.1. Response Time and Life Time. The response time of the electrode assembly (CPE8) was investigated in terms of change in potential with time for 0.01 and $0.001 \mathrm{M}$ solution of $\mathrm{Tl}(\mathrm{I})$ ion. All the measurements were performed at constant $\mathrm{pH}$ (5.2) of test solution. It was observed that the electrode CPE8 reached to a stable potential in a very short time of about $6 \mathrm{~s}$. To evaluate the reversibility of the electrode the effect of concentration on potential response of the electrode was investigated for whole concentration range. The results were obtained by changing the concentration from higher to lower $\left(1.0 \times 10^{-2}-10^{-8} \mathrm{M}\right)$ and then from lower to higher concentration; the variation of potential with time for CPE8 was studded for whole concentration range from lower $(1.0 \times$ $\left.10^{-8}-1.0 \times 10^{-2} \mathrm{M}\right)$ for CPE8. The average response time of the electrode assembly was almost the same for both sequences. Thus the electrode CPE8 is sufficiently reversible. The $\mathrm{pH}$ of test solution was maintained with the help of phosphate buffer solution (Figure 2).

The large surface area and covalent interaction of mesoporous silica (SBA-15) with modifier TMPA avoids the leaching of electrode components that may occur from physical

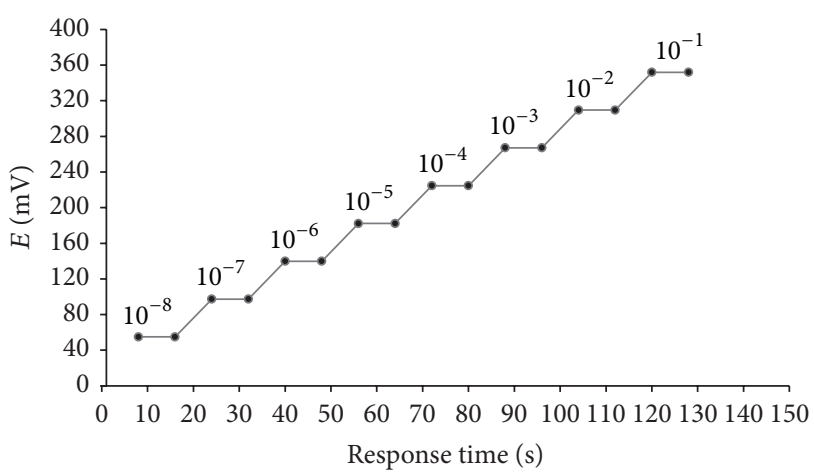

Figure 2: Variation of potential with time for CPE8.

TABLE 2: Change in slope and detection limit with time for CPE8.

\begin{tabular}{lcc}
\hline Time (months) & Slope (mV/dec. of activity) & LOD \\
\hline 1 & $42.4 \pm 1.0$ & $6.0 \times 10^{-9} \mathrm{M}$ \\
2 & $42.4 \pm 1.0$ & $6.0 \times 10^{-9} \mathrm{M}$ \\
3 & $42.4 \pm 1.0$ & $6.0 \times 10^{-9} \mathrm{M}$ \\
4 & $42.4 \pm 1.0$ & $6.0 \times 10^{-9} \mathrm{M}$ \\
5 & $42.4 \pm 1.0$ & $6.0 \times 10^{-9} \mathrm{M}$ \\
6 & $42.4 \pm 1.0$ & $6.0 \times 10^{-9} \mathrm{M}$ \\
7 & $42.4 \pm 1.0$ & $6.0 \times 10^{-9} \mathrm{M}$ \\
8 & $41.3 \pm 1.0$ & $6.0 \times 10^{-9} \mathrm{M}$ \\
9 & $40.1 \pm 1.0$ & $8.0 \times 10^{-9} \mathrm{M}$ \\
10 & $39.3 \pm 1.0$ & $8.6 \times 10^{-9} \mathrm{M}$ \\
11 & $36.2 \pm 1.0$ & $1.2 \times 10^{-8} \mathrm{M}$ \\
12 & $33.8 \pm 1.0$ & $6.7 \times 10^{-8} \mathrm{M}$ \\
13 & $32.1 \pm 1.0$ & $1.5 \times 10^{-7} \mathrm{M}$ \\
\hline
\end{tabular}

encapsulation. Thus electrode based on modified silica (SBA15 or MCM41) can show stable response towards target species for a very long time. In the present study the life time of the electrode CPE8 was investigated with the help of change in LOD and slope of calibration curve. It was observed that the LOD and slope remain the same for a period of 10 months. However after 10 months small change in slope and detection limit was observed. Thus the CPE8 can be used for the selective determination of $\mathrm{Tl}(\mathrm{I})$ for more than 10 months. The electrode CPE8 used all the measurements at least three times in a week for more than one hour (Table 2).

3.2. Effect of $p H$. The effect of $\mathrm{pH}$ on the response of the carbon paste electrode modified with organofunctionalized silica was studded in the range of $0-10.6$. As shown in Figure 3 the potential of the electrode remains almost the same in a $\mathrm{pH}$ range of 1.6-8.3. However significant drift in potential was observed beyond this $\mathrm{pH}$ range. The sharp change in potential at $\mathrm{pH}<1.6$ was due to either protonation of bonding material of electrode or competition kinetics of binder and hydrogen ion or both at electrode solution interface. At higher $\mathrm{pH}$ potential decreases due to the formation of hydroxy complex of $\mathrm{Tl}(\mathrm{I})$ ion. The $\mathrm{pH}$ of test solution was adjusted by phosphate buffer $\left(\mathrm{NaH}_{2} \mathrm{PO}_{4}-\mathrm{H}_{3} \mathrm{PO}_{4}\right)$ solution and hexamine- $\mathrm{HCl}$ buffer solution. 


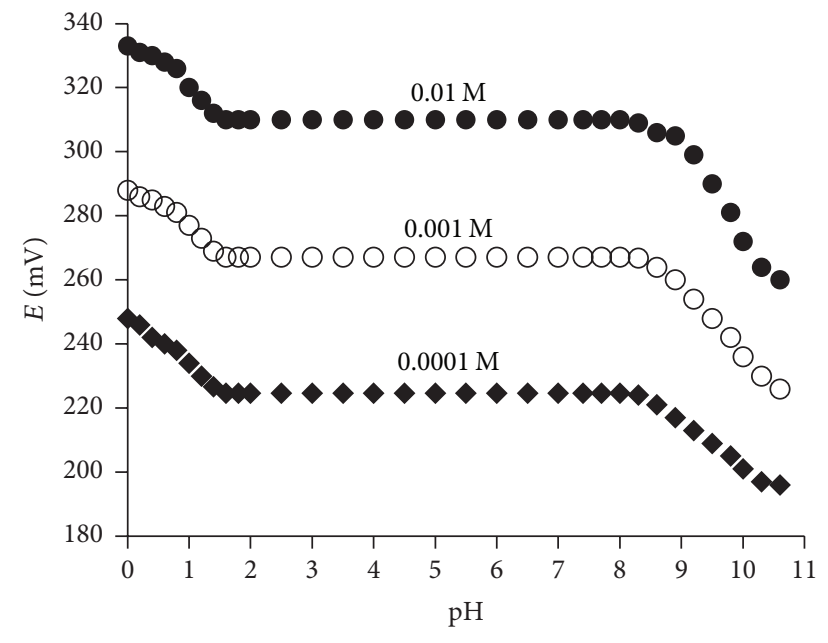

FIGURE 3: Effect of $\mathrm{pH}$ on potential response of CPE8.

TABLE 3: Selectivity coefficients of various interfering ions (B).

\begin{tabular}{lc}
\hline Interfering ion B & Selectivity coefficient $\left(K_{\mathrm{Ho}, \mathrm{B}}^{\mathrm{MPM}}\right)$ \\
\hline $\mathrm{Al}(\mathrm{III})$ & $4.3 \times 10^{-5}$ \\
$\mathrm{Ga}(\mathrm{III})$ & $1.3 \times 10^{-5}$ \\
$\mathrm{Ho}(\mathrm{III})$ & $1.3 \times 10^{-5}$ \\
$\mathrm{La}(\mathrm{III})$ & $1.6 \times 10^{-5}$ \\
$\mathrm{Eu}(\mathrm{III})$ & $1.7 \times 10^{-5}$ \\
$\mathrm{Nb}(\mathrm{III})$ & $1.6 \times 10^{-5}$ \\
$\mathrm{Dy}(\mathrm{III})$ & $1.8 \times 10^{-5}$ \\
$\mathrm{Bi}(\mathrm{III})$ & $1.3 \times 10^{-5}$ \\
$\mathrm{Hg}(\mathrm{II})$ & $1.3 \times 10^{-5}$ \\
$\mathrm{~Pb}(\mathrm{II})$ & $1.3 \times 10^{-4}$ \\
$\mathrm{Cd}(\mathrm{II})$ & $1.2 \times 10^{-4}$ \\
$\mathrm{Zn}(\mathrm{II})$ & $1.1 \times 10^{-4}$ \\
$\mathrm{Cu}(\mathrm{II})$ & $1.3 \times 10^{-5}$ \\
$\mathrm{Ag}(\mathrm{I})$ & $1.1 \times 10^{-5}$ \\
$\mathrm{Na}(\mathrm{I})$ & $3.0 \times 10^{-4}$ \\
$\mathrm{~K}(\mathrm{I})$ & $1.3 \times 10^{-4}$ \\
$\mathrm{Li}(\mathrm{I})$ & $1.7 \times 10^{-5}$ \\
\hline
\end{tabular}

3.3. Calculation of Selectivity Coefficient. The selectivity of electrode is an important parameter which dictates selectivity of the electrode toward a specific ion in presence of other interfering ions. In the present study the selectivity coefficient of CPE8 was calculated by match potential method (MPM) (Table 3). The potential of the reference solution was calculated by adding $0.001 \mathrm{M}$ solution of $\mathrm{Tl}(\mathrm{I})$ (primary ion). In another experiment, a secondary ion (interfering ion) was added to the same reference solution of $\mathrm{Tl}(\mathrm{I})$ ion, until the observed potential matches the potential of original reference solution. The selectivity coefficient, $K^{\mathrm{MPM}}$, of complexation kinetics of ligand and $\mathrm{Tl}(\mathrm{I})$ in presence of other cations was then calculated by the following [12-14]:

$$
K^{\mathrm{MPM}}=\frac{a_{\mathrm{Tl}(\mathrm{I})}}{a_{\mathrm{M}}},
$$

where $a_{\mathrm{Tl}(\mathrm{I})}$ is activity of $\mathrm{Tl}(\mathrm{I})$ ion and $a_{\mathrm{M}}$ is activity of other tested cations. The selectivity coefficient of CPE8 towards $\mathrm{Tl}(\mathrm{I})$ is compiled in Table 3 . It was observed that the selectivity coefficients of $\mathrm{Tl}(\mathrm{I})$ selective electrode $\mathrm{CPE} 8$ towards various tested metal ions are less than $3.6 \times 10^{-5}$. Thus CPE8 can be used for the selective determination of $\mathrm{Tl}(\mathrm{I})$ ion in presence of these interfering ions.

3.4. Thermal Stability of the Electrode Assembly. The thermal stability of the electrode assembly was investigated in terms of thermal temperature coefficient $\left(d E^{\circ} / d T\right)$ of the cell and electrode. The potentials of the cell were calculated at different temperatures $\left(20-50^{\circ} \mathrm{C}\right)$ and at zero concentration of $\mathrm{Tl}(\mathrm{I})$ ions. The curve of $E_{\text {Cell }}^{\circ}$ versus $(t-25)$ was found to be a straight line and has a slope of $-2.7 \times 10^{-4} \mathrm{~V} /{ }^{\circ} \mathrm{C}$ :

$$
E_{\text {Cell }}^{\circ}=E_{\text {Cell }}^{\circ}\left(25^{\circ} \mathrm{C}\right)+\frac{d E_{\text {Cell }}^{\circ}}{d T}(t-25) \text {. }
$$

The standard electrode potential was calculated by

$$
E_{\text {electrode }}^{\circ}=E_{\text {Cell }}^{\circ}+E_{\text {reference }}^{\circ}
$$

The curve of $E_{\text {electrode }}^{\circ}$ versus $(t-25)$ also gives a straight line with a slope of $-3.2 \times 10^{-5} \mathrm{~V} /{ }^{\circ} \mathrm{C}$. The small values of thermal temperature coefficient of cell $\left(-2.7 \times 10^{-4} \mathrm{~V} /{ }^{\circ} \mathrm{C}\right)$ and electrode $\left(-3.2 \times 10^{-5} \mathrm{~V} /{ }^{\circ} \mathrm{C}\right)$ suggest that the electrode $(\mathrm{CPE} 8)$ is sufficiently stable within the investigated temperature range.

The response characters of the electrode were compared with the previously reported best polymeric membrane and carbon paste electrodes (Table 4).

\section{Analytical Application}

The electrode (CPE8) was successfully applied as indicator electrode for the titration of $20 \mathrm{~mL}$ of $0.01 \mathrm{M} \mathrm{TlNO}_{3}$ solution with standard EDTA $(0.01 \mathrm{M})$ solution at $\mathrm{pH} 5.0$. It was observed that the electrode potential sharply decreases at the end point of the titration. Thus the CPE8 can be used as an indicator electrode for the direct determination of total thallium content of the solution (Figure 4). The CPE8 was also applied as an indicator electrode in sequential titration of binary $\left(\mathrm{Br}^{-}+\mathrm{Cl}^{-}\right)$or ternary mixtures $\left(\mathrm{Br}^{-}+\mathrm{SCN}^{-}+\right.$ $\mathrm{Cl}^{-}$) of different anions. The successive variation of potential indicates the equivalent points for different anions. The equivalence point at titration curves (Figures 5 and 6) was found to be satisfactory with the solubility products of $\mathrm{TlBr}$, TlSCN, and $\mathrm{TlCl}$, respectively.

The practical utility of the electrode (CPE8) was investigated by recovery of $\mathrm{Tl}(\mathrm{I})$ ion from different synthetic water samples. The result, as the average of three separate determinations, is shown in Table 5. The data presented in Table 5 clearly shows that the recovery of the $\mathrm{Tl}(\mathrm{I})$ ion from different samples is in good agreement with the added value and the values obtained by AAS. It is very important to mention here that the $\mathrm{Tl}(\mathrm{I})$ ion is determined as the total metal content of the solution instead of specific compound of thallium. 
TABLE 4: Comparison study of CPE8 with previously reported electrodes.

\begin{tabular}{lccc}
\hline Type of electrode & Concentration range $(\mathrm{M})$ & Slope (mV/decay) & Reference \\
\hline PVC membrane & $1.0 \times 10^{-6}-1.0 \times 10^{-2}$ & 55 & {$[15]$} \\
PVC membrane & $5.0 \times 10^{-8}-1.0 \times 10^{-1}$ & $57.27 \pm 0.4$ & {$[16]$} \\
PVC membrane & $6.4 \times 10^{-7}-1.0 \times 10^{-2}$ & $56 \pm 0.2$ & {$[17]$} \\
Carbon paste & $5.8 \times 10^{-6}-2.9 \times 10^{-3}$ & & {$[18]$} \\
Carbon paste & $1.0 \times 10^{-8}-1.0 \times 10^{-1}$ & $42.4 \pm 1.0$ & This work \\
\hline
\end{tabular}

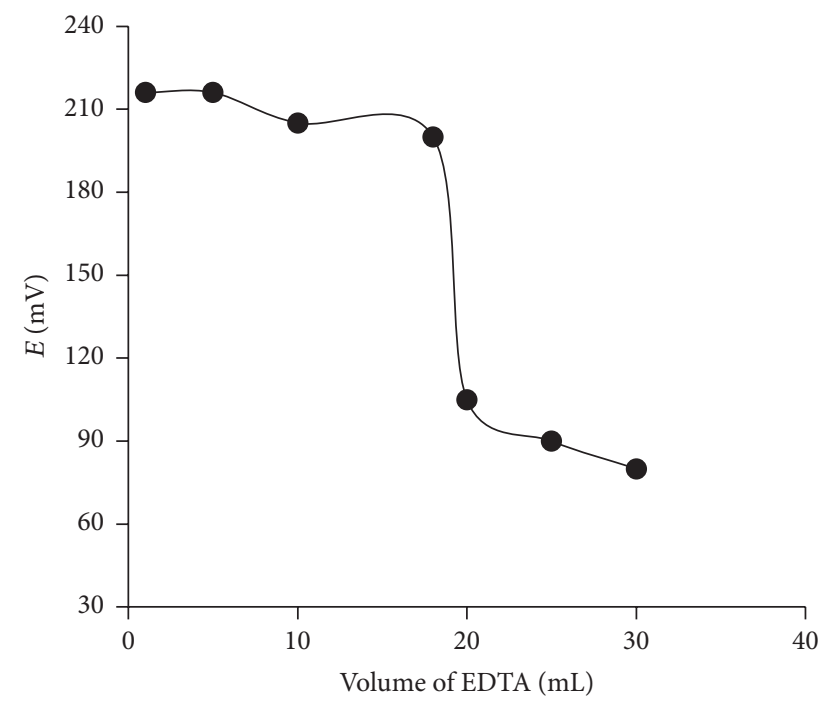

FIgure 4: Titration curve of Tl(I) with EDTA using CPE8 as indicator electrode.

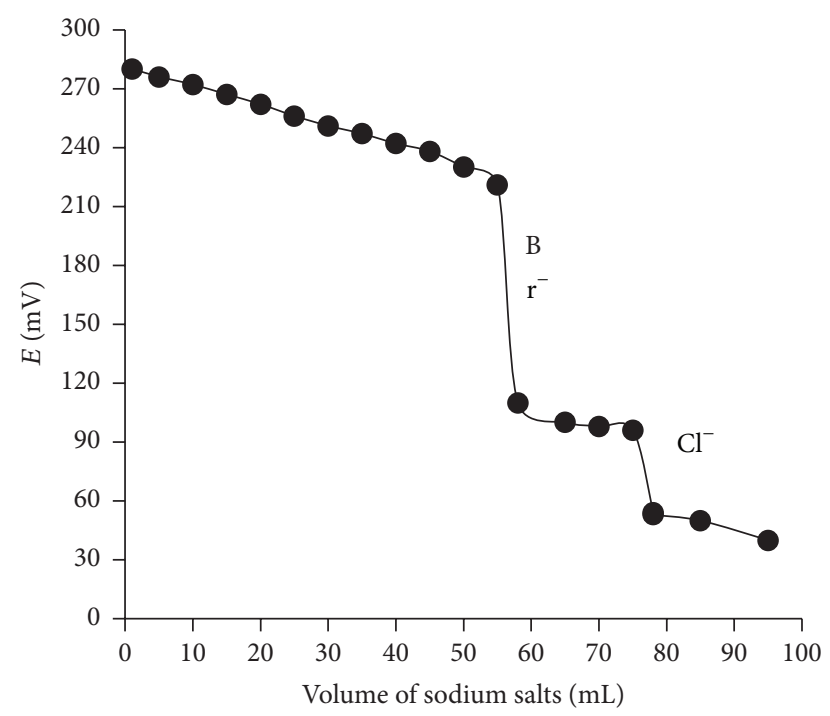

Figure 5: Titration curve of $10 \mathrm{~mL}(0.01 \mathrm{M}) \mathrm{TlNO}_{3}$ with $0.003 \mathrm{M}$ $\mathrm{NaBr}$ and $0.1 \mathrm{M} \mathrm{NaCl}$ solutions.

\section{Conclusion}

Chemically modified silica (SBA-15) based electrode has been constructed and used for the selective determination of $\mathrm{Tl}(\mathrm{I})$ in various synthetic water samples. The mesoporous silica

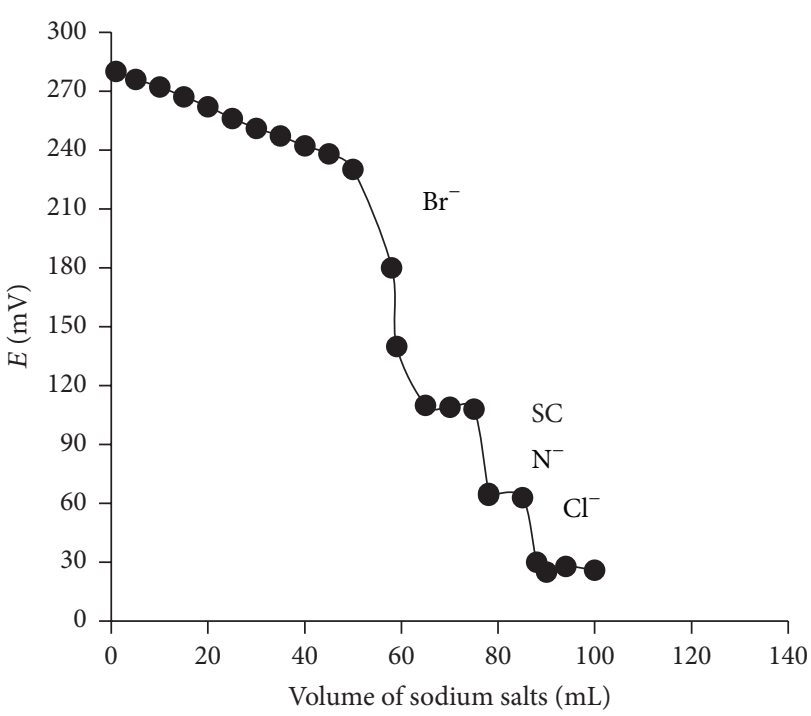

Figure 6: Titration curve of $10 \mathrm{~mL}(0.01 \mathrm{M}) \mathrm{TlNO}_{3}$ with $0.003 \mathrm{M}$ $\mathrm{NaBr}, 0.1 \mathrm{M} \mathrm{NaSCN}$, and $0.1 \mathrm{M} \mathrm{NaCl}$ solutions.

TABle 5: Recovery of Tl(I) ion by CPE8 from different water samples.

\begin{tabular}{lccc}
\hline \multirow{2}{*}{ Sample } & \multirow{2}{*}{ Added (M) } & \multicolumn{2}{c}{ Recovery (\%) } \\
& & CPE8 & AAS \\
\hline Tap water 1 & 0.0005 & 100.2 & 100.3 \\
Tap water 2 & 0.0004 & 100.0 & 100.1 \\
River water & 0.0003 & 102.3 & 102.4 \\
Hair sample & 0.0003 & 101.4 & 101.5 \\
\hline
\end{tabular}

(SBA-15) was chemically modified by 3-(triethoxysilyl)propyl amine (TESPA) and 2-[5-(chloromethyl)-1,2,4-oxadiazol-3yl]-3-methylpyridine as electroactive modifier. The electrode of the composition of 10\% TMPA-SBA-15, 75\% graphite powder, and $15 \%$ paraffin oil shows the best possible response in terms of slope $(42.4 \pm 1.0, \mathrm{mV} /$ decay of activity), working concentration range $\left(1.0 \times 10^{-8}-1.0 \times 10^{-1} \mathrm{M}\right)$ with LOD of $6.0 \times 10^{-9} \mathrm{M}$. The CPE8 reached the equilibrium valve of potential in a very short time of about $8 \mathrm{~s}$ and could be used for a period of more than 10 months without any divergence in response characters. The electrode CPE8 was also used as an indicator electrode for the titration of $0.01 \mathrm{M}$ $\mathrm{TINO}_{3}$ solution with standard EDTA solution and sequential titration of mixture of different anions. 


\section{Competing Interests}

The authors declare that they have no competing interests.

\section{References}

[1] A. Saha, "Thallium toxicity: a growing concern," Indian Journal of Occupational and Environmental Medicine, vol. 9, no. 2, pp. 53-56, 2005.

[2] A. Saddique and C. D. Peterson, "Thallium poisoning: a review," Veterinary and Human Toxicology, vol. 25, no. 1, pp. 16-22, 1983.

[3] A. Kassim, M. Rezayi, S. Ahmadzadeh et al., "A novel ionselective polymeric membrane sensor for determining thallium(I) with high selectivity," Materials Science and Engineering, vol. 17, no. 1, Article ID 012010, pp. 1-7, 2011.

[4] K. S. Park, S. O. Jung, S. S. Lee, and J. S. Kim, "Thailium(I)selective electrodes based on calix [4] pyrroles," Bulletin of the Korean Chemical Society, vol. 21, pp. 909-912, 2000.

[5] T. Katsu, K. Ido, K. Takaishi, and H. Yokosu, "Thallium(I)selective membrane electrodes based on calix[6]arene or calix[5]arene derivatives," Sensors and Actuators, B: Chemical, vol. 87, no. 2, pp. 331-335, 2002.

[6] M. Etienne, J. Bessiere, and A. Walcarius, "Voltammetric detection of copper(II) at a carbon paste electrode containing an organically modified silica," Sensors and Actuators B: Chemical, vol. 76, no. 1-3, pp. 531-538, 2001.

[7] R. Huirache-Acuña, R. Nava, C. L. Peza-Ledesma et al., "SBA-15 mesoporous silica as catalytic support for hydrodesulfurization catalysts-review," Materials, vol. 6, no. 9, pp. 4139-4167, 2013.

[8] Y. Han and D. Zhang, "Ordered mesoporous silica materials with complicated structures," Current Opinion in Chemical Engineering, vol. 1, no. 2, pp. 129-137, 2012.

[9] W. J. J. Stevens, K. Lebeau, M. Mertens, G. van Tendeloo, P. Cool, and E. F. Vansant, "Investigation of the morphology of the mesoporous SBA-16 and SBA-15 materials," The Journal of Physical Chemistry B, vol. 110, no. 18, pp. 9183-9187, 2006.

[10] Z. Stani and S. Gairousi, "Carbon paste electrodes in potentiometry: the state of the art and applications in modern electroanalysis (review)," Sensing in Electoanalysis, vol. 6, pp. 89-128, 2011.

[11] M. R. Ganjali, Z. Rafiei-Sarmazdeh, T. Poursaberi, S. J. Shahtaheri, and P. Norouzi, "Dichromate ion-selective sensor based on functionalized SBA-15/ionic liquid/MWCNTs/graphite," International Journal of Electrochemical Science, vol. 7, no. 3, pp. 1908-1916, 2012.

[12] E. Bakker, E. Pretsch, and P. Bühlmann, "Selectivity of potentiometric ion sensors," Analytical Chemistry, vol. 72, no. 6, pp. 1127-1133, 2000.

[13] Y. Umezawa, P. Bühlmann, K. Umezawa, K. Tohda, and S. Amemiya, "Potentiometric selectivity coefficients of ionselective electrodes part I. Inorganic cations (technical report)," Pure and Applied Chemistry, vol. 72, no. 10, pp. 1851-2082, 2000.

[14] Y. Umezawa, K. Umezawa, and H. Sato, "Selectivity coefficients for ion-selective electrodes: recommended methods for reporting $\mathrm{K}_{\mathrm{A}, \mathrm{B}}{ }^{\text {pot }}$ values (technical report)," Pure and Applied Chemistry, vol. 67, no. 3, pp. 507-518, 1995.

[15] T. Katsu, K. Ido, K. Takaishi, and H. Yokosu, “Thallium(I)selective membrane electrodes based on calix[6]arene or calix[5] arene derivatives," Sensors and Actuators, B: Chemical, vol. 87, no. 2, pp. 331-335, 2002.

[16] K. S. Park, S. O. Jung, S. S. Lee, and J. S. Kim, "Thallium(I)selective electrodes based on calix[4]pyrroles," Bulletin of the Korean Chemical Society, vol. 21, no. 9, pp. 909-912, 2000.
[17] S. V. Kharitonov, Y. V. Zarembo, and V. I. Zarembo, "Novel thallium(III) solid-contact ion-selective electrode with electropolymerized transducer," Electroanalysis, vol. 18, no. 13-14, pp. 1354-1362, 2006.

[18] K. Vytras, E. Khaled, J. Jezkova, and B. N. Barsoum, "Studies on the potentiometric thallium(III)-selective carbon paste electrode and its possible applications," Fresenius' Journal of Analytical Chemistry, vol. 367, no. 2, pp. 203-207, 2000. 

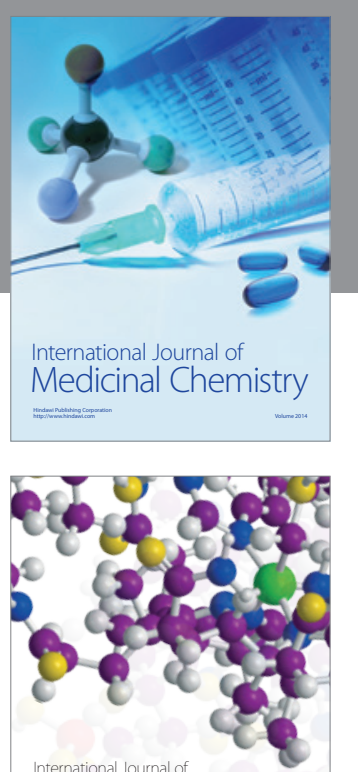

Carbohydrate Chemistry

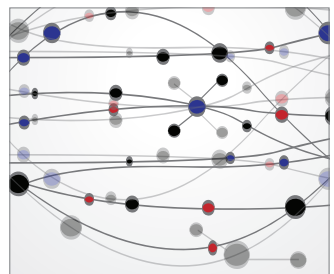

The Scientific World Journal
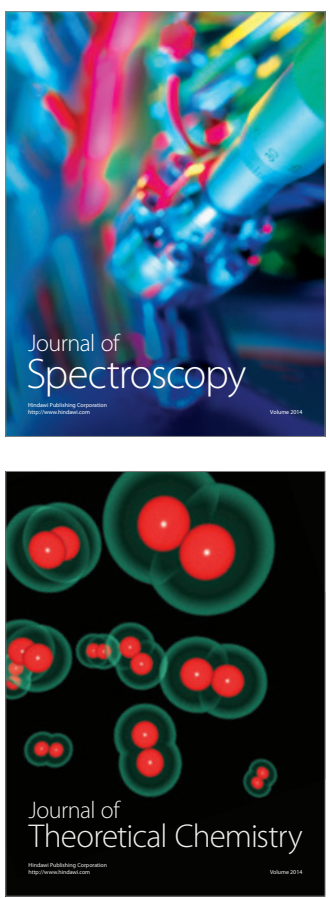
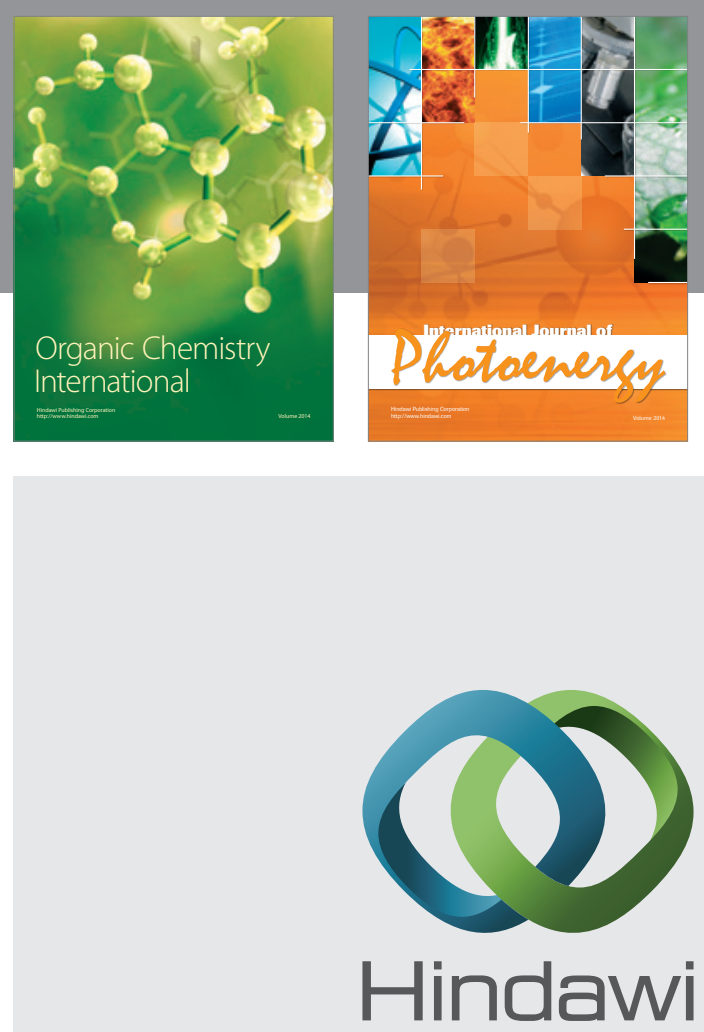

Submit your manuscripts at

http://www.hindawi.com

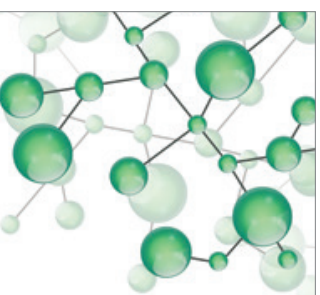

International Journal of

Inorganic Chemistry

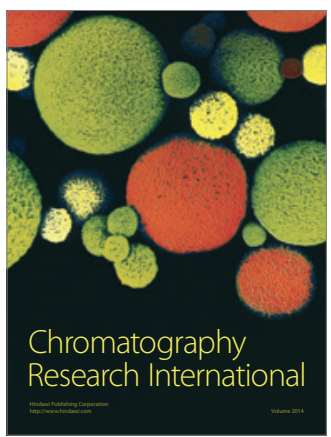

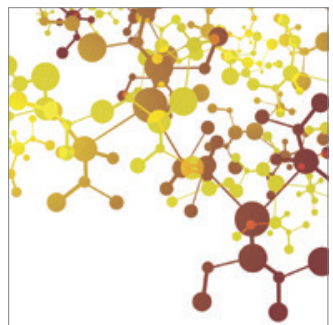

Applied Chemistry
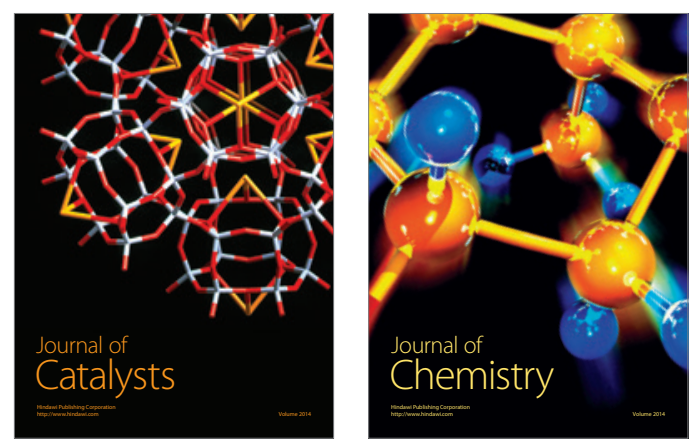
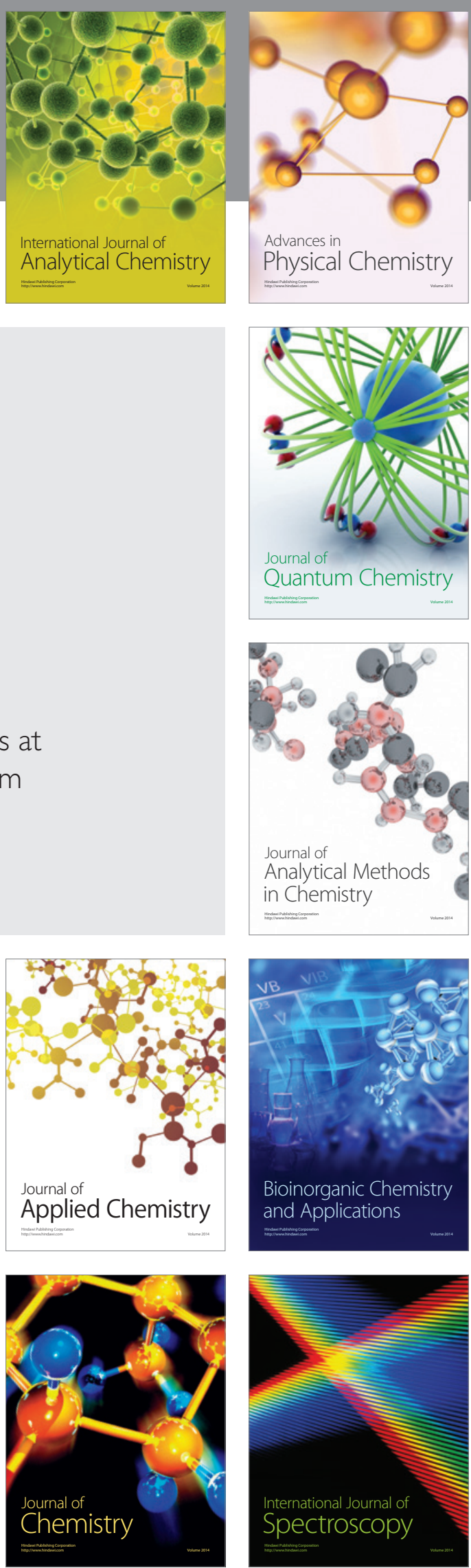